\title{
Zika Vírus
}

Cynthia Molina Bastos. TelessaudeRS/UFRGS, Programa de Pós Graduação em Epidemiologia, Universidade Federal do Rio Grande dos Sul. Porto Alegre, RS, Brasil. cynthia.bastos@telessauders.ufrgs.br (Autora correspondente)

Otávio Pereira D’Avila. TelessaudeRS/UFRGS, Universidade Federal do Rio Grande do Sul (UFRGS). Porto Alegre, RS, Brasil. otaviopereiradavila@gmail.com

Roberto Nunes Umpierre. TelessaudeRS/UFRGS, Faculdade de Medicina, Programa de Pós Graduação em Epidemiologia, Universidade Federal do Rio Grande do Sul (UFRGS). Porto Alegre, RS, Brasil. rnumpierre@gmail.com Marcelo Rodrigues Gonçalves. TelessaudeRS/UFRGS, Faculdade de Medicina, Programa de Pós Graduação em Epidemiologia, Universidade Federal do Rio Grande do Sul (UFRGS). Porto Alegre, RS, Brasil. marcelorog@gmail.com Erno Harzheim. TelessaudeRS/UFRGS, Faculdade de Medicina, Programa de Pós Graduação em Epidemiologia, Universidade Federal do Rio Grande do Sul (UFRGS). Porto Alegre, RS, Brasil. ernoharz@ terra.com.br

Michele, 32 anos, procura a Unidade de Saúde por manchas na pele, há 24 horas, levemente pruriginosas. A paciente retornou de uma viagem há dois dias. Viajou por cidades do Nordeste brasileiro durante dez dias. Ela suspeita de que a reação alérgica se deve ao protetor solar, que pode ter causado a irritação na sua pele. Conforme relata, no último dia das férias, precisou comprar um produto novo, de uma marca que nunca havia utilizado. Além disso, refere que o quadro alérgico está tão importante que não colocou as lentes de contato, devido ao olho levemente vermelho, sem prurido e com discreto lacrimejamento e já iniciou o colírio para conjuntivite alérgica, corticoide tópico nasal e loratadina $10 \mathrm{mg}$.

Quando questionada em relação a outros sintomas associados, refere cansaço, dizendo que adorou a viagem, mas que retornar de férias é sempre mais cansativo. Afirma que não se alimentou direito nos últimos dois dias, o voo durou mais de 12 horas devido às conexões aéreas e que ela está com dor no corpo, mais importantes nas articulações, "toda dolorida". Cefaleia e sensação de peso na cabeça e mal-estar. Não sabe se teve febre, pois não aferiu, entretanto, quando questionada, acha possível. Nega alterações no hábito intestinal ou urinárias. Refere tosse e discreta secreção hialina nasal, após ter chegado ao seu apartamento, que ficou fechado por dez dias.

Michele é professora universitária, natural de Mossoró, no Rio Grande do Norte, católica, casada. Foi morar na região Sul do país, com seu esposo, após assumir um cargo na universidade local. Eles planejam engravidar no ano de 2016, inclusive realizaram sorologias e esclareceram dúvidas na última consulta na unidade de saúde.

Fonte de financiamento: declaram não haver. Parecer CEP: não se aplica. Conflito de interesses: declaram não haver. Procedência e revisão por pares: revisado por pares. Recebido em: 07/03/2016. Aprovado em: 10/03/2016. 
Segundo anotações do prontuário médico, a paciente apresenta diversas atopias, com quadros de exacerbação de conjuntivite alérgica, dermatite atópica e rinossinusites alérgicas mais importantes no inverno e na primavera. Entretanto, tem bom controle dos sintomas com uso de corticoides tópicos nos meses de inverno e primavera. Uso de anticoncepcional oral.

Ao exame físico, a paciente apresenta bom estado geral, eutrófica, temperatura axilar de 37,4 graus, sinais vitais sem alteração. Pele com exantema maculopapular, distribuído por todo corpo, sem descamação, sem preservar áreas específicas. Olhos com hiperemia de conjuntiva, sem secreção aparente. Rinoscopia e oroscopia sem alterações. Ausculta pulmonar limpa. Extremidades perfundidas, aquecidas e sem edema.

\section{PERGUNTA}

Baseado na história e exame físico, qual o diagnóstico mais provável?
a) Zika Vírus.
b) Reação alérgica aguda de etiologia ainda desconhecida.
c) Parvovirose.
d) Exacerbação da dermatite atópica e da conjuntivite alérgica.

\section{Discussão}

a) A infecção por Zika Vírus é assintomática em pelo menos $80 \%$ dos pacientes. Nos casos sintomáticos, mais de $90 \%$ apresentam exantema maculopapular difuso, eventualmente pruriginoso, sem evolução específica, entretanto, com relatos na literatura de distribuição craniocaudal sem preservar áreas específicas do corpo. A febre, quando acontece, não costuma ser alta. A conjuntivite, hiperemia de conjuntiva, sem secreção purulenta e não pruriginosa acompanha os casos. Artralgia, edema periarticular também podem estar presentes. Como todos os outros quadros virais, os sintomas constitucionais como anorexia, astenia, cansaço, mialgia e cefaleia podem estar presentes, normalmente de forma branda e sem comprometimento importante. ${ }^{1,2}$

A definição de caso suspeito de Zika Vírus adotada no Brasil é: pacientes que apresentem exantema maculopapular pruriginoso, acompanhado de pelo menos dois dos seguintes sintomas: febre ou hiperemia conjuntival sem secreção, prurido ou edema articular. ${ }^{3}$

A paciente refere que viajou para um local do país que conhecidamente o vírus está em circulação e o início dos sintomas ocorreu em período inferior a 15 dias. Independentemente da viagem, quadros compatíveis com a definição de caso suspeito adotada pelo Ministério da Saúde devem ser notificados para Vigilância do município, visto que a coleta do exame confirmatório deve ser realizada nos primeiros cinco dias de sintomas da doença. A vigilância adequada pelos profissionais da Atenção Primária à Saúde é muito importante na identificação dos casos suspeitos, principalmente em áreas onde a circulação do vírus, ou seja, transmissão autóctone, ainda não esteja bem estabelecida.

Avaliando o caso especificamente, é importante observar que a paciente está em idade fértil, já manifestou desejo de engravidar. Então, precisa ser avaliada em relação a possível gravidez. As orientações importantes para esses casos suspeitos de Zika Vírus são eliminação de depósitos que sirvam de criadouro para o mosquito Aedes aegypti, proteção do domicílio, com uso de telas em portas 
e janelas, dormir em ambientes fechados, sempre que possível com ar condicionado ou ventilador, uso de proteção individual (roupas e/ou repelentes). Hidratação. Não utilizar anti-inflamatórios não esteroides. Reavaliação (presencial ou contato por telefone) para conhecimento da evolução do caso em 24/48 horas. Orientação em relação aos sinais de fraqueza muscular associados ao Guillain-Barré.

b) A possibilidade de reação alérgica é plausível, considerando que a paciente apresenta história prévia de atopias. Entretanto, além do quadro de hiperemia de conjuntiva não pruriginosa, ela refere um quadro constitucional, ainda que brando, associado aos sinais: refere dor articular, cansaço, sensação de febre e cefaleia.

c) Os adultos normalmente apresentam sorologias para o Parvovírus B19, mas é possível que desenvolvam um quadro oligossintomático. As expressões clínicas incluem eritema infeccioso e normalmente são acompanhadas de sintomas de vias aéreas. ${ }^{4}$

d) A dermatite atópica é uma doença da pele com períodos de exacerbação e remissão, frequentemente caracterizada por eczemas e liquenificação nas regiões flexurais, quadro mais típico para idade adulta. Frequentemente, a conjuntivite alérgica é pruriginosa. ${ }^{5}$

\section{Resposta: Alternativa A}

\section{Referências}

1. Secretaria Estadual da Saúde do Rio Grande do Sul, Universidade Federal do Rio Grande do Sul. Guia médico de enfrentamento ao Aedes aegypti para serviços de Atenção Primária à Saúde no Rio Grande do Sul [Internet]. Porto Alegre (RS):UFRGS; 2016. [Citado 7 Mar 2016]. Disponível em: https://www.ufrgs.br/rscontraaedes/materiais/protocolo_manual_ aedes_medicos_20160128_ver009_link_Ift.pdf

2. Centers for Disease Control and Prevention. Zika Virus [internet]. Atlanta (GA): CDC; 2016. [Citado 7 Mar 2016]. Disponível em: www.cdc.gov/zika

3. Brasil. Ministério da Saúde. Febre pelo vírus Zika: uma revisão narrativa sobre a doença [Internet]. Boletim Epidemiológico. 2015;46(26) [Citado 10 Mar 2016]. Disponível em: http://portalsaude.saude.gov.br/images/pdf/2015/agosto/26/2015-020publica----o.pdf

4. Cakirca M, Karatoprak C, Ugurlu S, Zorlu M, Kıskaç M, Çetin G. Parvovirus B19 infection as a cause of acute myositis in an adult. Rev Bras Reumatol. 2015;55(2):185-8. DOI: https://dx.doi.org/10.1016/j.rbr.2013.06.005

5. Castro APM, Solé D, Rosário Filho NA, Jacob CMA, Rizzo MCFV, Fernandes MFM, et al. Guia prático para o manejo da dermatite atópica - opinião conjunta de especialistas em alergologia da Associação Brasileira de Alergia e Imunopatologia e da Sociedade Brasileira de Pediatria. Rev Bras Alerg Imunopatol. 2006;29(6):268-82. 